\title{
THE INFLUENCE OF DENITROGENATION ON THE RESPONSE OF ANESTHETIZED DOGS TO INTRAVENOUSLY INJECTED OXYGEN
}

\author{
BY RAYMOND E. WESTON AND LEONARD KAREL \\ (From the Toxicology Section, Medical Division, Edgewood Arsenal, Md.)
}

(Received for publication November 8, 1946)

\section{INTRODUCTION}

A marked clinical improvement in critically ill human subjects after the intravenous administration of oxygen has been reported by a number of investigators ( 1 to 5 ) despite the fact that only about 1.5 to 10 per cent of the calculated basal oxygen requirement was injected. However, in normal and in anoxemic experimental animals, other workers (6 to 10) have observed not only rapid, shallow breathing but also decreased rather than increased oxygen content of the arterial blood following the intravenous injection of oxygen at rates of 0.21 to $2.3 \mathrm{ml}$. per $\mathrm{kgm}$. per minute. The paradoxical anoxemia has been attributed to interference with the pulmonic oxygenation of the blood by the formation of multiple oxygen emboli in the pulmonary capillaries (7). The accompanying respiratory changes, which are abolished by bilateral vagotomy, have been considered (10) as similar to the tachypnea observed in dogs after the production of pulmonary capillary emboli by the intravenous injection of starch granules (11).

Recently, in seeking a simple and effective means of extra-pulmonic oxygenation for supportive treatment in severe, acute pulmonary edema, we became interested in the possibilities of intravenous oxygen administration, and particularly in the cause and prevention of the hypothesized emboli resulting from this procedure. From theoretical considerations, it became apparent that, since the nitrogen tension of the blood and tissues normally is high ( $573 \mathrm{~mm}$.), gaseous nitrogen present in the blood must enter intravenously injected oxygen bubbles, as in a tonometer. Consequently, if all the oxygen injected were absorbed by the reduced venous hemoglobin before the blood reached the right heart, residual nitrogen bubbles would remain to obstruct the pulmonary capillaries. In recent years, the analogous role of dissolved nitrogen in the bubble formation of decompression sickness and aero-embolism has been demonstrated and the value of prophylactic denitrogenation by inhalation of 99.6 per cent oxygen has been well established (12 to 18). To explore the interrelationship between nitrogen tension and intravascular bubble formation and the anoxemia following intravenously administered oxygen, in the present experiments, comparisons were made between the effects of oxygen administered intravenously to anesthetized dogs without prior denitrogenation and after the nitrogen saturation of the blood and tissues was reduced by continuous intratracheal exposure to 99.6 per cent oxygen before and during the intravenous administration of oxygen.

\section{EXPERIMENTAL}

Twenty-six healthy, normal, adult, mongrel dogs weighing from 7.7 to $34.1 \mathrm{kgm}$. were anesthetized by the intravenous injection of approximately $25 \mathrm{mgm}$. of sodium pentobarbital per $\mathrm{kgm}$. body weight. A glass, L-shaped cannula was inserted into the exposed trachea and tied in place with heavy, silk ligatures. The femoral artery and vein were exposed bilaterally for blood sampling and for intravenous oxygen administration. The state of anesthesia was maintained by additional pentobarbital injections as required.

Denitrogenation was accomplished by continuous administration for 3 to 4 hours of dry 99.6 per cent commercial oxygen, or occasionally 95 per cent oxygen- 5 per cent carbon dioxide, supplied to the animals on demand at low pressures and without re-breathing by means of an Army Air Force, low resistance, A-16 valve, attached to the tracheal cannula by rubber connections as described previously (19). In 3 experiments with very large dogs, the reducing valve leading to the demand valve offered too much resistance at peak inspiratory flows. Therefore, oxygen was supplied from a Douglas-Haldane bag, with the oxygen removed being continuously replaced from a tank connected to the bag.

The intravenously administered oxygen was bubbled through water and, then, continuously injected into the femoral veins through two $1 / 2$-inch, 27-gauge needles. The rate of the injection was measured by a calibrated, capillary orifice flowmeter interposed between the water bottle and the rubber tube leading to the needles. Respiratory rates were observed before, during, and after 
intravenous oxygen administration. Additional details of experimental procedure are given below.

By direct femoral arterial or venous puncture, blood samples were collected in heparinized, air-free syringes, which were immediately sealed with mercury, and stored at $0^{\circ} \mathrm{C}$. Determinations of nitrogen content and oxygen content and capacity were performed in duplicate generally by the Edwards-Roughton-Scholander techniques $(20,21)$. Occasionally, additional checks were made by the usual Van Slyke manometric method (22). In some experiments, nitrogen contents were determined by a shorter manometric method recently described by Horvath and Roughton (23).

In an effort to avoid the pulmonary passive congestion and edema which Drinker (24) has observed in anesthetized dogs after prolonged immobilization, the animals, which were restrained in a supine position when blood samples were drawn or intravenous oxygen was administered, were moved frequently during the experiment.
Despite this precaution, however, on autopsy many exhibited some congestion.

Until the day of the experiment, diets consisting of fox chow, milk, horse meat, and water ad libitum were permitted.

\section{RESULTS}

1. The effect of intravenous oxygen administration on the arterial oxygen content of denitrogenated dogs

An initial series of experiments confirmed the observations of others (6 to 10) that oxygen administered intravenously to anesthetized dogs at rates as low as $1 \mathrm{ml}$. per $\mathrm{kgm}$. per minute (12 to 30 per cent of the basal oxygen requirement) rapidly produced marked increases in respiratory rates and, often, greater than 25 per cent decreases

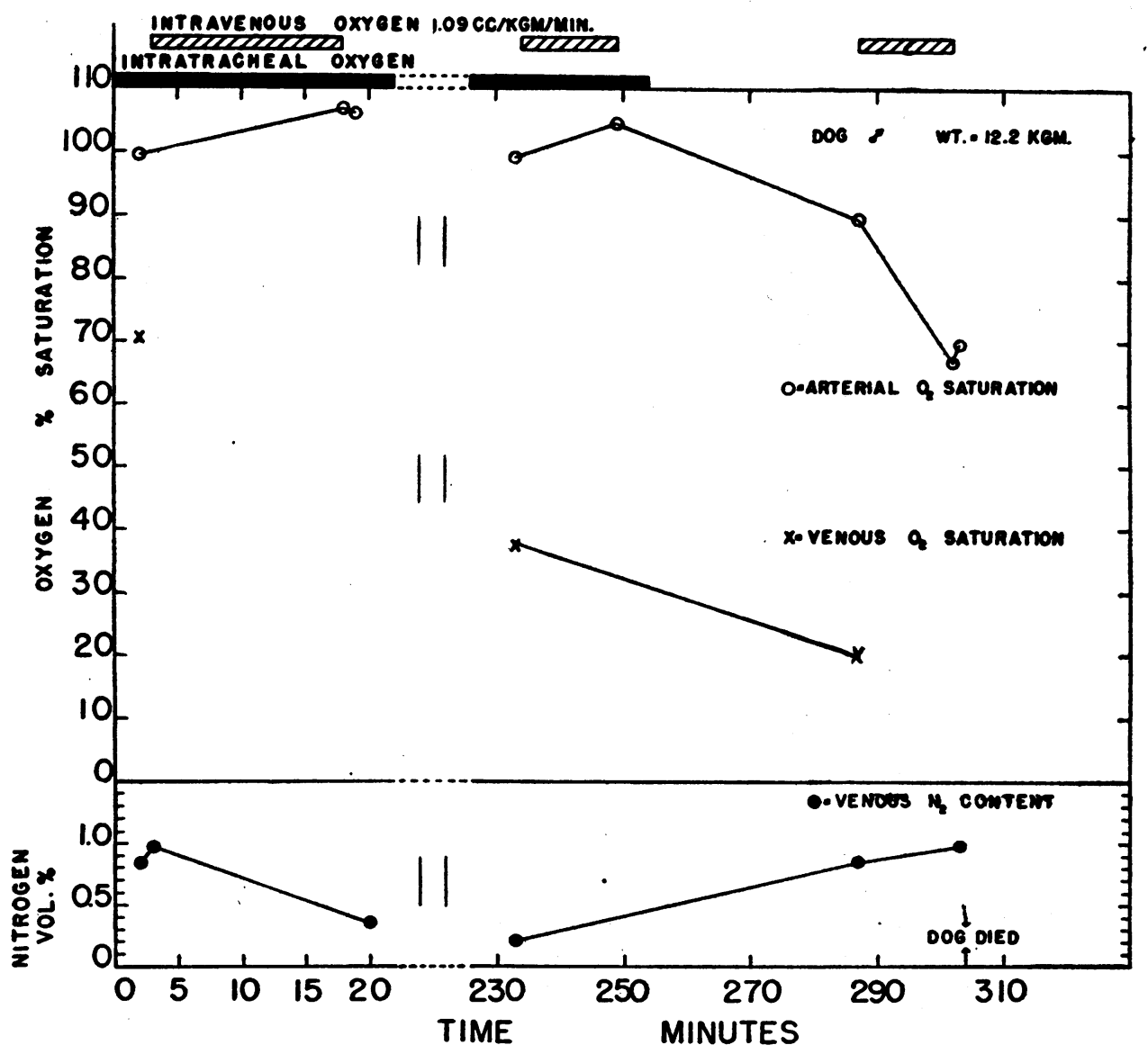

Fig. 1. Arterial Oxygen Saturation and Venous Nitrogen Content in a 12.2 Kgy. Anesthetized Dog Before and After Intravenous Injection of Oxygen During and Following Denitrogenation by Continuous Intratracheal Administration of 99.6 Per Cent Oxygen

Intravenous oxygen was injected at a rate corresponding to 21.9 per cent of the calculated basal requirement. 


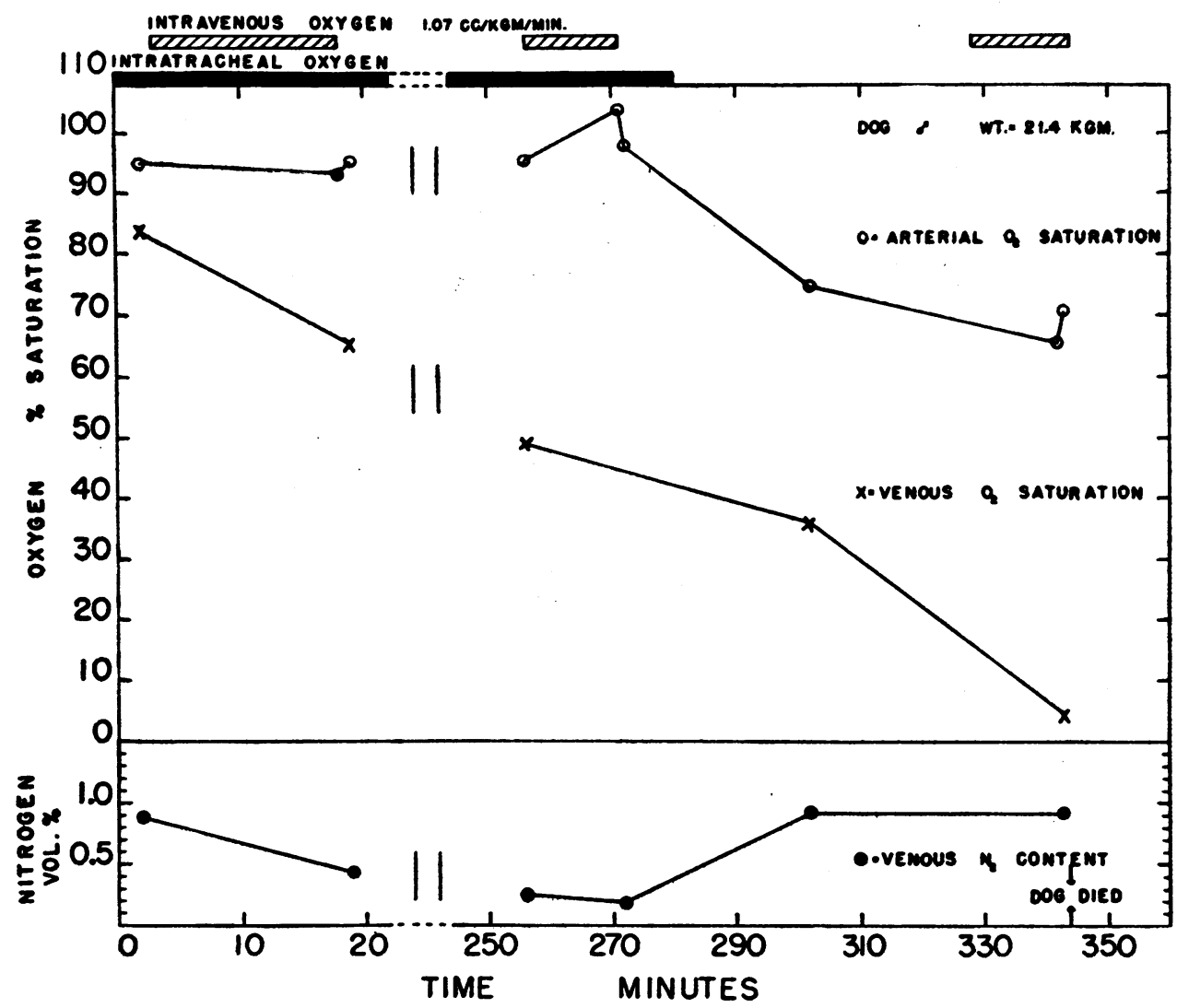

Fig. 2. Arterial Oxygen Saturation and Venous Nitrogen Content in a 21.4 Kga. Anesthetized Dog Before and After Intravenous Injection of Oxygen During and Following Denitrogenation by Continuous Intratracheal Administration of 99.6 Per CENT OXYGEN

Intravenous oxygen was injected at a rate corresponding to 24.3 per cent of the calculated basal requirement.

in arterial oxygen content. A second series of experiments revealed that intravenously injecting $1 \mathrm{ml}$. of oxygen per $\mathrm{kgm}$. per minute for 20 -minute periods in tracheotomized, anesthetized dogs which

TABLE I

Pertinent data indicating changes in arterial oxygen content following the intravenous injection of oxygen for 20 minutes in tracheotomized, anesthetized dogs, denitrogenated by continuous exposure to 99.6 per cent oxygen for 3 to 4 hours

\begin{tabular}{|c|c|c|c|c|}
\hline \multirow{2}{*}{$\begin{array}{l}\text { Dog } \\
\text { no. }\end{array}$} & \multirow{2}{*}{$\begin{array}{c}\mathrm{O}_{2} \text { Injected } \\
\text { Expressed as } \\
\text { per cent of } \\
\text { basal require- } \\
\text { ment }\end{array}$} & \multirow{2}{*}{$\begin{array}{c}\text { Venous } \mathrm{N}_{2} \\
\text { content at } \\
\text { time of } \\
\text { injection } \\
\text { of } \mathrm{O}_{2}\end{array}$} & \multicolumn{2}{|c|}{ Arterial $\mathrm{O}_{2}$ content } \\
\hline & & & $\begin{array}{c}\text { Before } \\
\text { injection } \\
\text { of } \mathrm{O}_{2}\end{array}$ & $\begin{array}{c}\text { After } \\
\text { injection } \\
\text { of } \mathrm{O}_{2}\end{array}$ \\
\hline $\begin{array}{l}1 \\
2 \\
3 \\
4\end{array}$ & $\begin{array}{c}\text { per cent } \\
12.5 \\
16.9 \\
17.3 \\
22.0 \\
33.1\end{array}$ & $\begin{array}{l}0.18 \\
0.27\end{array}$ & $\begin{array}{c}\text { ume per ce } \\
19.6 \\
19.9 \\
17.5 \\
19.6 \\
21.0\end{array}$ & $\begin{array}{l}15.0 \\
20.8 \\
18.4 \\
18.0 \\
16.0\end{array}$ \\
\hline
\end{tabular}

had been denitrogenated for from 3 to 4 hours, as described above, by exposure to 99.6 per cent oxygen usually produced falls in arterial oxygen content, frequently of the magnitude of 5 volumes per cent, although occasionally there occurred slight increases. Table I gives the pertinent data for 4 representative experiments in which venous nitrogen content was reduced to 0.18 to 0.27 volumes per cent before oxygen ( 12.5 to 33.1 per cent of the basal requirement) was administered intravenously.

2. Effect of intravenous oxygen on the arterial oxygen saturation in dogs before and after denitrogenation by exposure to 99.6 per cent oxygen

Binger, Brow, and Branch (11) found that inhalation of 90 per cent oxygen abolished the anoxemia observed in dogs after the production of 
multiple pulmonary capillary emboli by intravenous injection of starch suspensions. Therefore, the less marked fall in arterial oxygen content of the denitrogenated dogs following the injection of intravenous oxygen may have resulted not from the prophylactic denitrogenation but from therapeutic effects of the 99.6 per cent oxygen by means of which denitrogenation was achieved and maintained. Consequently, the following experiments were performed to determine whether the simultaneous administration of 99.6 per cent oxygen intratracheally without "complete" denitrogenation would also prevent the development of the anoxemia.
Figures 1 to 4 graphically illustrate 4 representative experiments in which intravenous oxygen was administered at rates of 1.03 to $1.09 \mathrm{ml}$. per $\mathrm{kgm}$. per minute to anesthetized dogs for three 15-minute periods as follows: (1) two.minutes after the start of the intratracheal exposure to 99.6 per cent oxygen and, therefore, presumably before denitrogenation was complete; (2) after 4 hours of intratracheal oxygenation to achieve marked denitrogenation; and (3) if the animal survived the 2 earlier injections, approximately 30 to 60 minutes after discontinuing the intratracheal oxygen to permit the animals to become renitrogenated by breathing air.

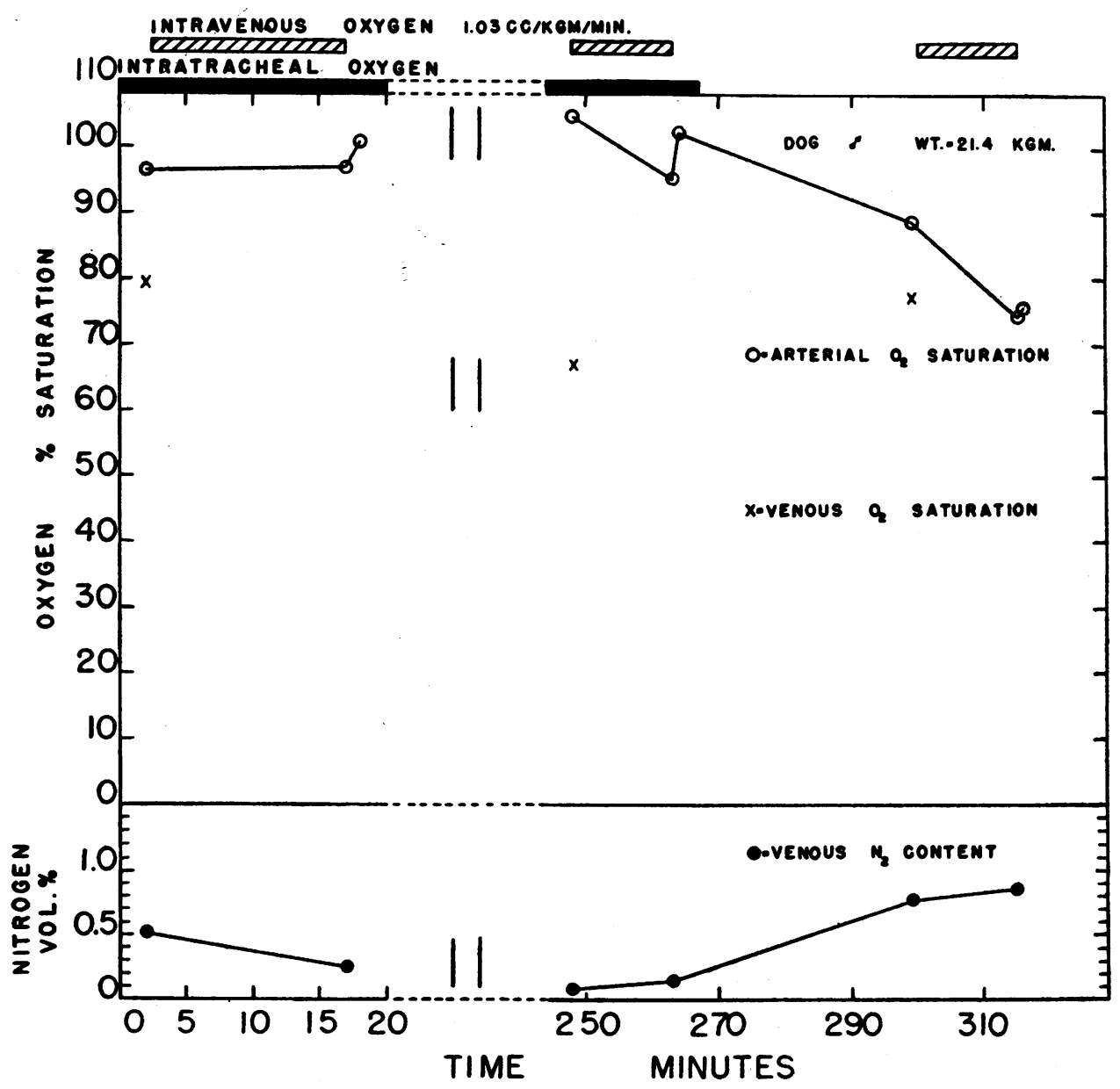

Fig. 3. Arterial Oxygen Saturation and Venous Nitrogen Content in a 21.4 Kgm. Anesthetized. Dog Before and After Intravenous Injection of Oxygen During and Following Denitrogenation by Continuous Intratracheal Administration of 99.6 Per Cent Oxygen

Intravenous oxygen was injected at a rate coresponding to 23.4 per cent of the calculated basal requirement. 


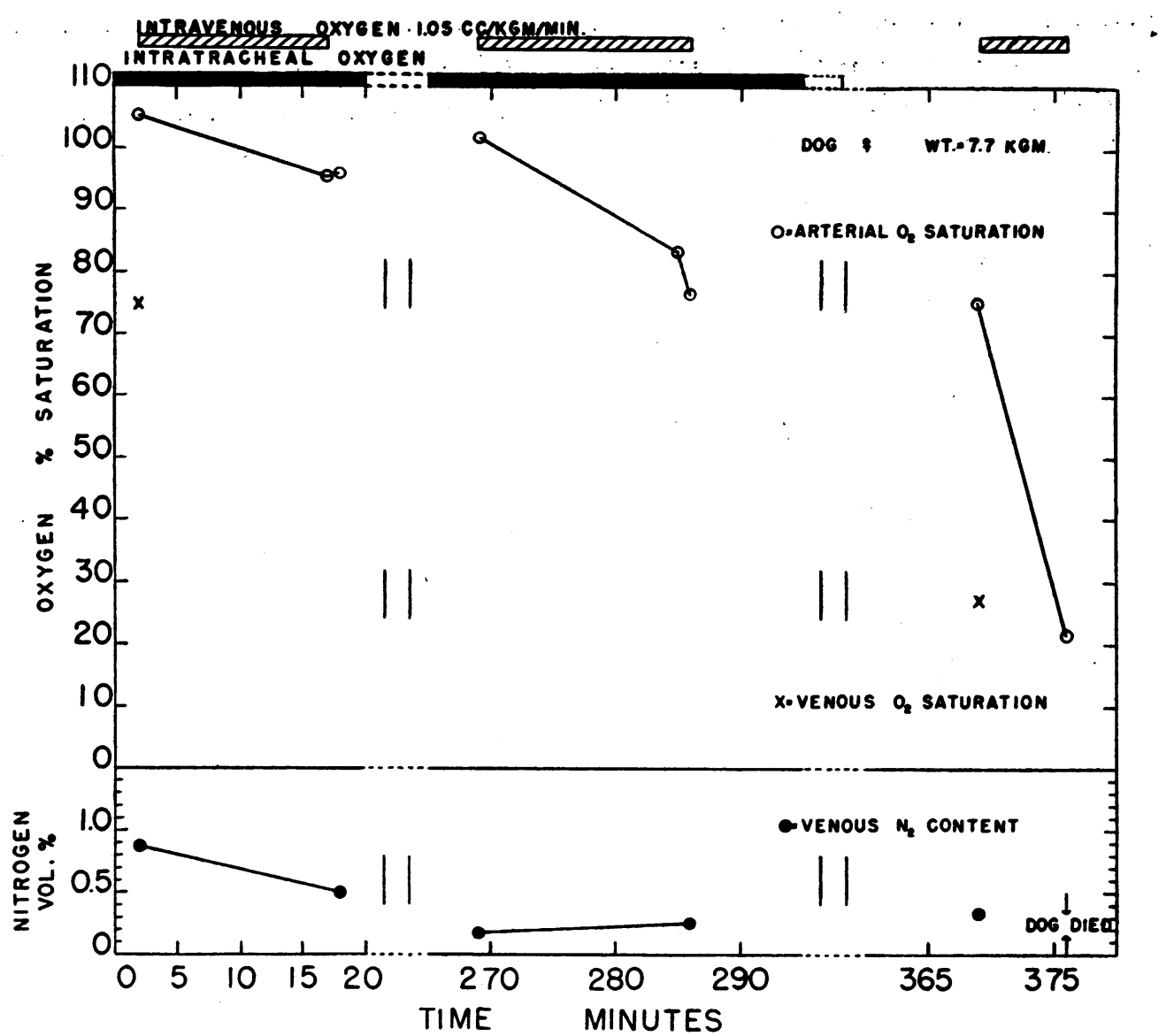

Fig. 4. Arterial Oxygen Saturation and Venous Nitrogen Content in a 7.7 Kgm. Anesthetized Dog Before and After Intravenous Injection of Oxygen During and Following Denitrogenation by Continuous Intratracheal Administration of 99.6 Per CENT OXYGEN

Intravenous oxygen was injected at a rate corresponding to 15.2 per cent of the calculated basal requirement.

In 2 of the animals (Figures 1,3 ) administration of intravenous oxygen 2 minutes after the start of intratracheal oxygen resulted in increases in oxygen saturation of the arterial blood. However, in both of these animals, the venous nitrogen content by the end of the 15-minute injection period had fallen to values of 0.36 volume per cent and 0.26 volume per cent respectively. During the first period of intravenous oxygenation in the other 2 animals, there was a fall in the arterial oxygen saturation, and the decrease in venous nitrogen content was not so marked; i.e., it fell from 0.89 and 0.87 volume per cent to 0.43 and 0.50 volume per cent, respectively ( $c f$. Figures 2 and 4). Similarly, when the intravenous oxygen in- jections were repeated after more complete denitrogenation, in 2 of the 4 animals, there was a rise (Figures 1,2), whereas in the other 2 there was a fall (Figures 3,4 ) in arterial oxygen saturation although the nitrogen contents of the venous blood at the start of the injection periods were $0.21,0.23$, 0.09 , and 0.15 volume per cent, respectively. Thus, in these experiments, there was no direct relationship between the nitrogen content of the venous blood and the response to intravenous oxygenation. However, the final intravenous injections of oxygen at the same rate, when the dogs were more completely nitrogenated and were breathing not oxygen but air, produced rapid, marked drops in arterial oxygen saturation in 3 of the animals and 
a moderate drop in the fourth, with death in 3 occurring within a few minutes after the cessation of the injection (Figures 1 to 4 ). In all instances, the injection of oxygen resulted in a sharp rise in respiratory rate, the increases being, respectively, from 24 to 120,40 to 70,19 to 116 , and 26 to 60 . It will be noted that the least renitrogenation and greatest fall in arterial oxygen saturation occurred in the dog represented by Figure 4. This animal, at autopsy, showed appreciable congestion of the lungs.
3. Effect of intravenously injected air on oxygen saturation in dogs

There was no significant difference in the response to intravenous oxygen of dogs when either more completely denitrogenated or only partially denitrogenated by exposure to intratracheal oxygen for 2 minutes before and during the 15-minute period of injection. As a result, it was not clear whether the lesser drop or slight rise in arterial oxygen saturation following intravenous oxygen injection in both the partially and more completely

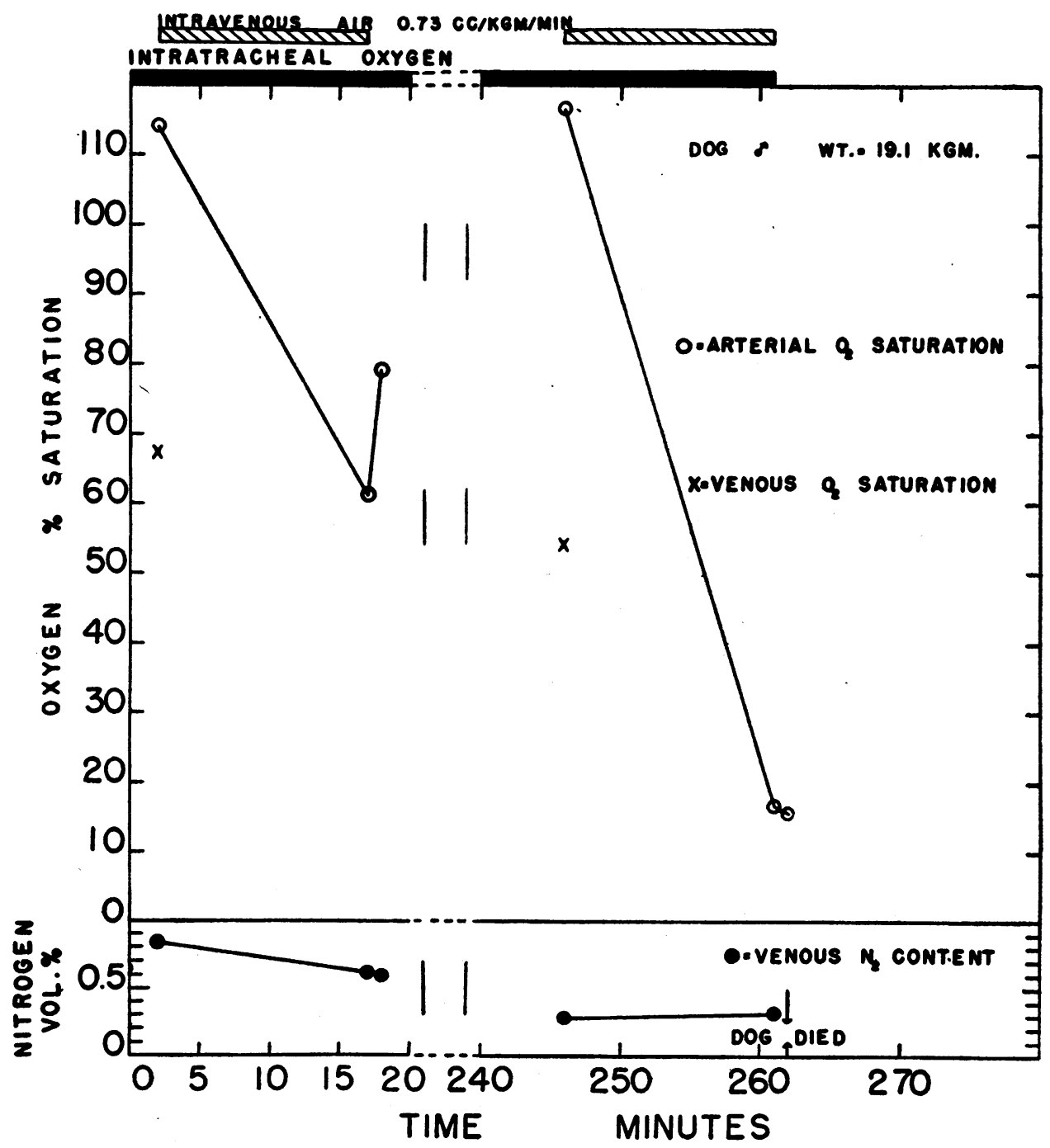

Fig. 5. Arterial Oxygen Saturation and Venous Nitrogen Content in a 19.1 Kgy. Anesthetized Dog Before and After the Intravenous Injection of Air During and Following Denitrogenation by Continuous Intratracheal Administration of 99.6 Per Cent Oxygen 


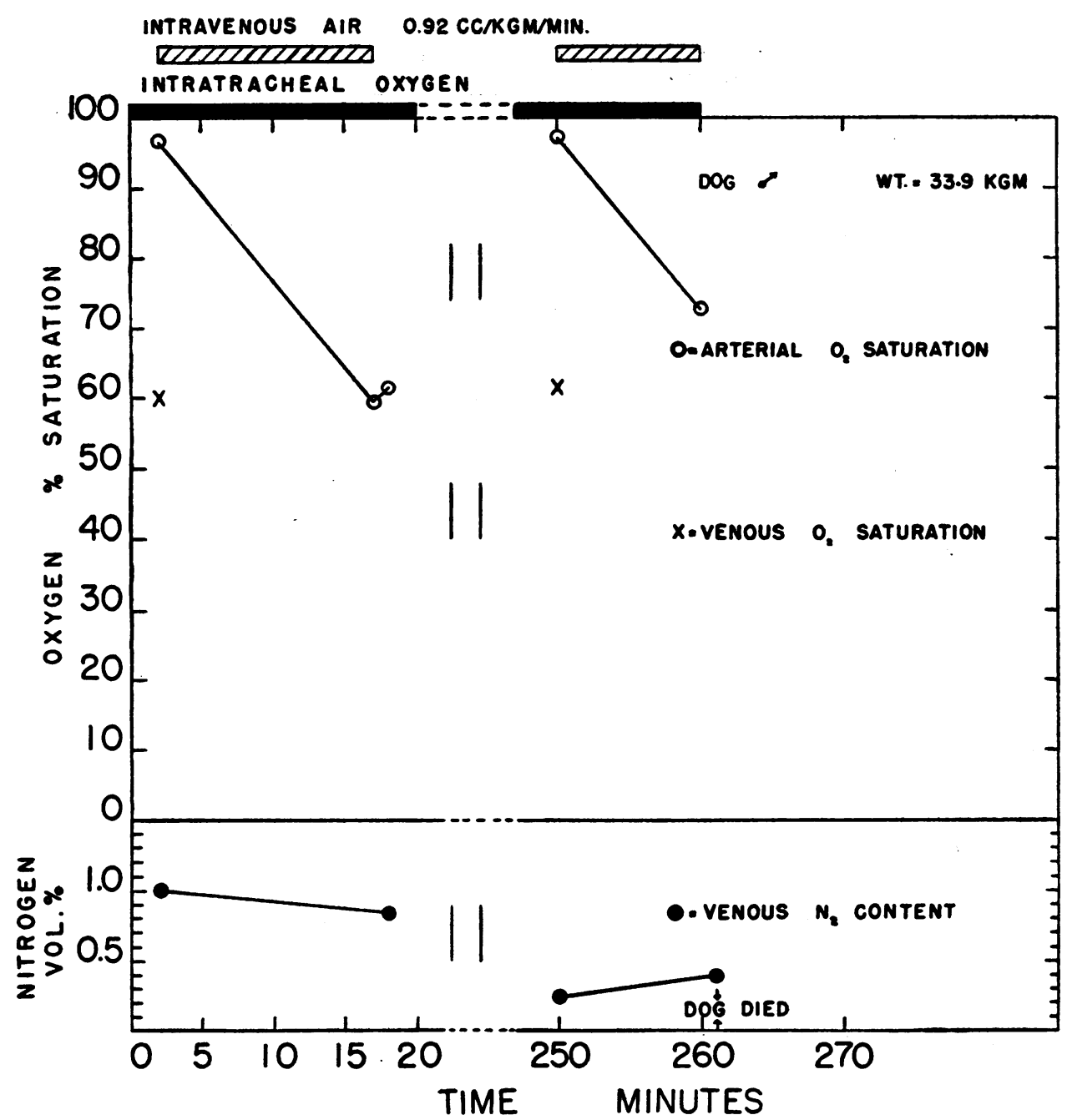

Fig. 6. Arterial Oxygen Saturation and Venous Nitrogen Content in a 33.9 Kgm. Anesthetized Dog Before and After the Intravenous Injection of Air During and Fozlowing Denitrogenation by Continuous Intratracheal Administration of 99.6 Per Cent Oxygen

denitrogenated dogs was a consequence of the beneficial effects of the prophylactic denitrogenation or of hyperventilation in the presence of the high intratracheal oxygen concentration. If the less severe reactions to intravenous oxygen resulted merely from hyperventilation due to bubble formation in the pulmonary capillaries of animals which were breathing high concentrations of oxygen, similar results should be obtained if the hyperventilation were produced by injection of an inert gas-even nitrogen itself-at comparable rates. Therefore, the previous experiment was re- peated in a series of dogs in which air rather than oxygen was injected intravenously.

Figures 5 to 7 illustrate typical experiments in which air was injected intravenously at rates of $0.73,0.92$, and $1.16 \mathrm{ml}$. per $\mathrm{kgm}$. per minute, respectively. In contrast to the injection of oxygen, the intravenous injection of air during simultaneous administration of intratracheal oxygen produced a rapid and extensive fall in arterial oxygen saturation both before and after considerable lowering of venous nitrogen content had been achieved, despite the marked hyperventilation which oc- 


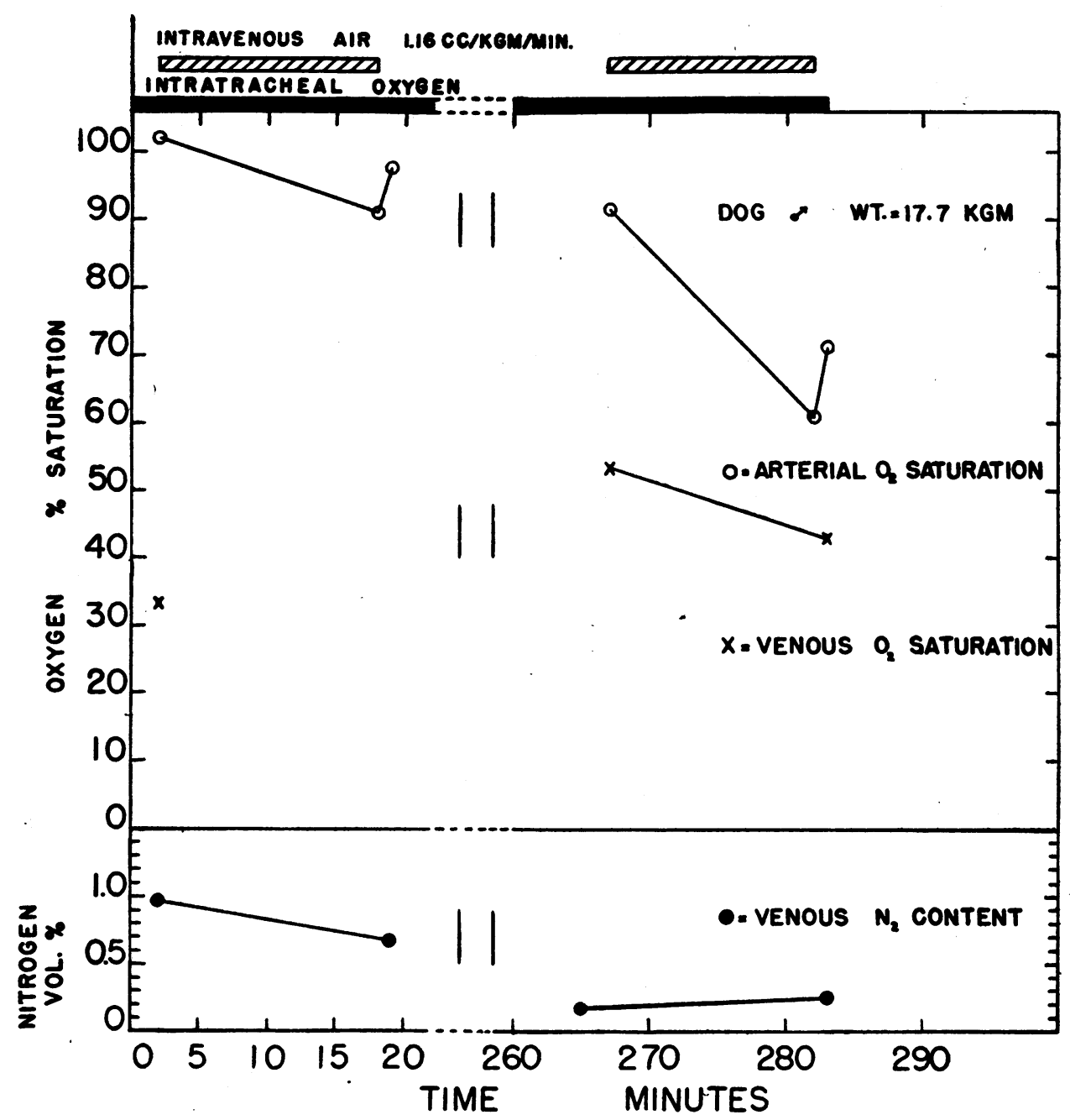

Fig. 7. Arterial Oxygen Saturation and Venous Nitrogen Content in a 17.7 Kgm. Anesthetized Dog Before and After the Intravenous Injection of Air During amd Following Denitrogenation by Continuous Intratracheal Administration of 99.6 Per Cent Oxygen

curred. In no experiment could the third injection without intratracheal oxygen be made, since the animals all died after the second injection, although in some ( $c f$. Figures 5,6 ) the intravenous air was injected at a much slower rate than was the intravenous oxygen.

4. The effect of injecting intravenous oxygen at very slow rates in normal anesthetized dogs without previous denitrogenation

Inasmuch as there have been reports of marked clinical improvement in anoxemic human subjects who received prolonged intravenous injections of very small amounts of oxygen ( 1 to 5$)$, arterial and venous oxygen saturations were followed in pentobarbitalized dogs during the intravenous administration of oxygen at comparable rates for periods up to 3 hours. Because of the briefer duration of these experiments, reinforcing doses of pentobarbital were not required to maintain the anesthesia. In Figure 8, 3 such experiments are graphically presented.

In all 3 animals, although the venous oxygen saturation was only 44 per cent to 73 per cent at the start of the experiment, as would be expected in deeply barbitalized animals breathing air, the 
intravenous injection of oxygen at rates of 0.082 (A) to $0.345 \mathrm{ml}$. per $\mathrm{kgm}$. per minute (B) resulted in continued fall of both arterial and venous oxygen saturation. In one experiment (Figure 8, B), the animal died after 150 minutes although the oxygen administered intravenously was only 7.4 per cent of the basal requirement.

The decline in oxygen saturation in all 3 animals and the death of the 1 animal must have been related to the intravenously administered oxygen for the following reasons: (1) generally, in pentobarbitalized animals, the blood oxygen saturation does not decrease but increases after several hours as the anesthesia tends to lighten, (2) the only other experimental procedure to which these large dogs were subjected was the withdrawal of a total of 30 to $50 \mathrm{ml}$. of blood over a period of about 180 minutes, and (3) at autopsy, no other significant contributory pulmonary pathology was found.

The results of these studies are graphically illustrated in Table II.

TABLE II

Tabular summary of the representative general effects of intravenously administered oxygen and air on the respiration and arterial oxygen saturation of denitrogenated and nondenitrogenated, anoxemic dogs

\begin{tabular}{|c|c|c|c|c|c|c|}
\hline \multirow{2}{*}{$\begin{array}{l}\text { Sub- } \\
\text { stance } \\
\text { admin- } \\
\text { istered }\end{array}$} & \multicolumn{3}{|c|}{ Denitrogenated dogs } & \multicolumn{3}{|c|}{$\begin{array}{l}\text { Non-denitrogenated } \\
\text { anoxemic dogs }\end{array}$} \\
\hline & $\begin{array}{l}\text { Per cent } \\
\text { of basal } \\
\text { require- } \\
\text { ment }\end{array}$ & $\begin{array}{c}\text { Respir- } \\
\text { atory } \\
\text { rate }\end{array}$ & $\begin{array}{c}\text { Arte- } \\
\text { rial O2 } \\
\text { satura- } \\
\text { tion }\end{array}$ & $\begin{array}{c}\text { Per cent } \\
\text { of basal } \\
\text { require- } \\
\text { ment }\end{array}$ & $\begin{array}{l}\text { Respir- } \\
\text { atory } \\
\text { rate }\end{array}$ & $\begin{array}{l}\text { Arte- } \\
\text { rial O2 } \\
\text { satura- } \\
\text { tion }\end{array}$ \\
\hline $\begin{array}{l}\text { i.v. } \mathrm{O}_{2} \\
\text { i.v. Air }\end{array}$ & 15.2 to 33.1 & $+t+$ & $-\overline{-}$ & 1.9 to 7.4 & $+t+$ & $-\overline{-}$ \\
\hline
\end{tabular}

\section{DISCUSSION}

The better response of dogs to the intravenous injection of oxygen at rates of approximately 1 $\mathrm{ml}$. per $\mathrm{kgm}$. per minute when intratracheal oxygen is administered simultaneously probably is not due solely to the beneficial effects of the inhaled oxygen. It should be recalled that when air was injected intravenously at equivalent or slower rates in dogs which were breathing 99.6 per cent oxygen after more or less denitrogenation, the fall in arterial oxygen saturation was as marked and rapid as that observed in animals given intravenous oxygen while breathing air (Figures 5 to 7 , 8), This indicates that the therapeutic effect of

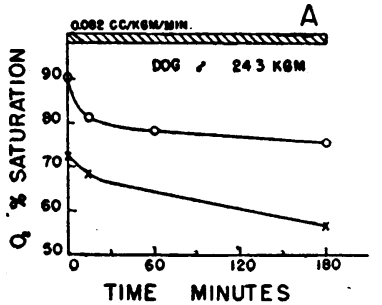

DONTRAVENOUS OXYGen - arterial o, saturatiom $x$ - venous a saturation
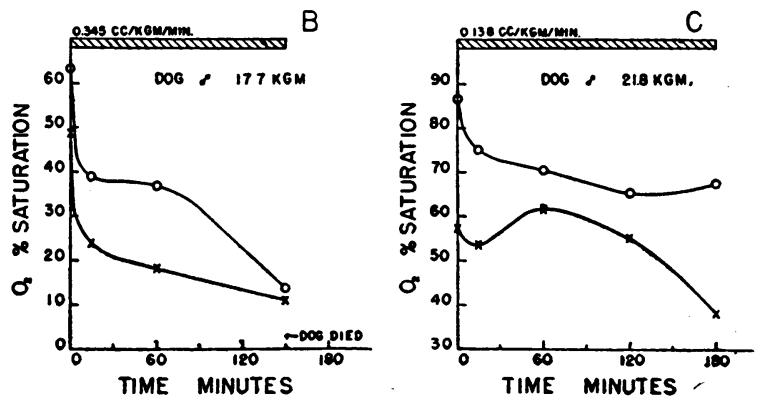

Fig. 8. Arterial and Venous Oxygen Saturation of Anesthetized, Tracheotomized Dogs Breathing AIR During the Continuous Intravenous InJection of Oxygen at Rates Which Corresponded to the Following Percentages of the Calculated Basal Requirement: 1.9 Per Cent in A, 7.4 Per Cent in B, ANd 3.2 Per Cent in C

99.6 per cent intratracheal oxygen alone is insufficient to effect the anoxemia produced by the hypothesized pulmonary emboli. Consequently, some other factor must be involved.

As noted above, Binger, Brow, and Branch (11) found that the administration of 90 per cent oxygen could abolish the anoxemia following production of multiple pulmonary capillary emboli by the intravenous injection of starch granules in dogs. Consequently, because the anoxemia following air injections was not compensated by the simultaneous administration of 99.6 per cent oxygen it could be argued that the air injections do not constitute an adequate control and that the 2 types of experiments reported in the present study differ only in that perhaps more absorption occurred from the oxygen bubbles than from the air bubbles, leaving smaller bubbles in the former case, producing a less severe anoxemia which could be better compensated by the inhaled 99.6 per cent oxygen.

However, because of the demonstrated role of dissolved gaseous nitrogen in the genesis and perpetuation of bubbles in the blood and tissues in decompression sickness and aero-embolism, it is probable that in fully nitrogenated animals, dis- 
solved nitrogen similarly enters the injected oxygen bubbles in accordance with Henry's law and that the less severe reaction to this procedure when intratracheal oxygen is simultaneously administered is a consequence of the denitrogenation achieved by the oxygen inhalations. In the denitrogenated dogs, on the other hand, as a result of the lower nitrogen tension, particularly of the blood, probably less nitrogen enters the injected oxygen bubbles which, therefore, may become smaller in size if oxygen is taken up by the reduced hemoglobin in the venous blood. In this regard, it is interesting to note that the initial and final increase in respiratory rate during intravenous oxygen injections in dogs simultaneously inhaling 99.6 per cent oxygen was markedly less than that observed during either intravenous oxygen injections in dogs breathing air or during air injections in dogs breathing 99.6 per cent oxygen, indicating that the oxygen bubbles in the denitrogenated animals possibly were of smaller size or less persistent than in the other animals.

The prolonged injections of intravenous oxygen at very slow rates in anesthetized dogs without denitrogenation reported in the present communication establish further the physiological hazard of this procedure. Despite the slow rate of injection and the initial post-barbiturate anoxemia, arterial and venous oxygen saturation continued to fall or to remain low throughout the injection period, with death occurring in 1 animal before the 180minute injection period was completed.

Moreover, several incidental experimental observations demonstrate that even with denitrogenation and simultaneous intratracheal oxygen, intravenous oxygen constitutes an added hazard rather than a therapeutic aid in the anoxemic state. In experiments with 3 very large dogs and a smaller reducing valve leading from the oxygen tank to the demand valve, the resistance to respiration was markedly increased at peak inspiratory flows. Consequently, these animals while being denitrogenated by oxygen inhalation became progressively more anoxemic because of the inspiratory resistance which produced an inadequate respiratory flow and, ultimately, pulmonary congestion and pulmonary edema. In one animal, for example, arterial oxygen saturation was 63.5 per cent, venous oxygen saturation was 30.9 per cent, and ve- nous nitrogen content was 0.23 per cent, when the injection of intravenous oxygen at a rate of $1 \mathrm{ml}$. per kgm. per minute (23.2 per cent of basal oxygen requirement) was begun. Within 14 minutes, respiration had stopped, and at 15 minutes no cardiac sounds were audible. Similar observations made on the 2 other animals indicate, in addition, that the failure of intravenous oxygen administration in the remaining denitrogenated dogs was not necessarily a consequence of any elevation in oxygen saturation of the venous blood, which might result from simultaneous inhalation of 99.6 per cent oxygen.

These experiments establish the practical therapeutic inadequacy of intravenous oxygen administration, even when the effect of gaseous nitrogen in the blood and tissues is minimized by prophylactic denitrogenation. Other considerations also make it evident that until some means of preventing bubble formation is developed, introduction of significant amounts of oxygen by injection into the venous blood will not be successful. For example, if oxygen is injected into peripheral vessels, the amount which can be absorbed rapidly before coalescence of bubbles occurs is limited immediately to that which will saturate fully the venous return from the areas drained. Because the peripheral blood flow is small in comparison with the total cardiac output, Goodwin et al. (25) attempted to inject oxygen into the inferior vena cava through a special catheter which produces small bubbles, but had no particular success in preventing the development of the usual signs and symptoms of pulmonary capillary embolization.

Moreover, as Adriani has noted recently (26), intravenously injected oxygen, like air, produces bubbles which are surrounded by a thin protein film through which neither nitrogen nor oxygen can penetrate too readily. Adriani explains the persistence of the emboli by quoting Langmuir (27) who suggested that the films are persistent and resistant, because the protein is denatured. Thus, any oxygen bubble introduced in the circulation will be only slowly absorbed even in markedly unsaturated blood. Therefore, successful extrapulmonic oxygenation probably will require not intravenous injection but some other technique for introducing oxygen into the blood without bubble formation. 
Cessation of the intravenous injection of oxygen was followed within 1 minute in a number of instances by a sudden and variable, but non-persistent, rise in the arterial oxygen saturation. A similar phenomenon was observed and is more fully commented upon by Goodwin et al. (25).

Because of the observations made by a number of workers regarding oxygen depression, following the inhalation of pure oxygen during anoxemia resulting from deep barbiturate anesthesia, and central nervous system depression (28), the objection may be raised that the intravenous administration of oxygen to anoxemic dogs under pentobarbital anesthesia can depress or completely check respiration. It should be pointed out that although oxygen depression is readily obtained in the intact pentobarbitalized dog, it is accompanied by an almost immediate precipitous fall in respiratory rate and depth, which may happen even after only 1 breath of pure oxygen. In the series of experiments currently being reported, however, the intravenous injection of oxygen to the anoxemic dogs produced not a decrease, but an increase in respiratory rate, suggesting that the stimulus of anoxemia to the carotid and aortic bodies had not been removed.

\section{SUM MARY}

1. The observations of others that oxygen administered intravenously to dogs at rates as low as $1 \mathrm{ml}$. per $\mathrm{kgm}$. per minute rapidly produced marked increases in respiratory rates and often greater than 25 per cent decreases in arterial oxygen content were confirmed.

2. Prior to the administration of intravenous oxygen, animals were denitrogenated in order to reduce the incidence of intravascular bubble formation.

3. In tracheotomized, anesthetized dogs denitrogenated by exposure to 99.6 per cent oxygen for 3 to 4 hours, the intravenous injection of oxygen at a rate of $1 \mathrm{ml}$. per $\mathrm{kgm}$. per minute for 20 minute periods usually produced falls in arterial oxygen content, frequently of the magnitude of 5 volumes per cent, although occasionally there occurred slight increases.

4. In dogs which were first denitrogenated and then renitrogenated by breathing air, the intravenous administration of oxygen at rates the same as those previously used produced a rapid, significant drop in arterial oxygen saturation in most instances, and, in some cases, death.

5. In contrast to the results obtained on injection of oxygen during the simultaneous administration of intratracheal 99.6 per cent oxygen, the intravenous injection of air under similar conditions produced a rapid, extensive fall in arterial oxygen saturation both before and after considerable lowering of venous nitrogen content had been achieved, despite the marked hyperventilation which occurred.

6. The intravenous injection of oxygen for $\mathbf{1 8 0}$ minutes at very slow rates $(0.082$ to $0.345 \mathrm{ml}$. per $\mathrm{kgm}$. per minute) in deeply anesthetized and anoxemic dogs breathing air also resulted in a continued fall of the arterial and venous oxygen saturation, although the amount of oxygen administered represented merely 1.9 to 7.4 per cent of the basal requirement.

7. It is suggested that because of the physiological and physical factors involved in bubble formation, successful extra-pulmonic oxygenation will require some technique by which oxygen can be introduced into the blood without the formation of bubbles.

8. Even with denitrogenation and simultaneous intratracheal oxygen, intravenous oxygen constitutes an added hazard rather than a therapeutic aid in the anoxemic state.

\section{ACKNOWLEDGMENTS}

The authors wish to acknowledge gratefully the technical assistance of Misses America Moreno, Josephine Schaffer, and T/4 Patricia A. Gogins, WAC.

\section{BIBLIOGRAPHY}

1. Neudörfer, A., Zur intravenösen Sauerstoffinfusion. Wien Klin. Wchnschr., 1905, 18, 89.

2. Tunnicliffe, F. W., and Stebbing, G. F., The intravenous injection of oxygen gas as a therapeutic measure. Lancet, 1916, 2, 321.

3. Singh, I., and Shah, M. J., Intravenous injection of oxygen under normal atmospheric pressure. Lancet, 1940, $1,922$.

4. Ziegler, E. E., The intravenous administration of oxygen. J. Lab. \& Clin. Med., 1941, 27, 222.

5. Jacobi, M., Klein, B., Rascoff, H., Kogut, B., Auerbach, R. W., and Jennings, J. E., The effect of intravenous administration of oxygen on shock in in dogs and in human beings. Arch. of Surg., 1946, $52,42$.

6. Stuertz, E., Ueber intravenöse Sauerstoffinfusion. Ztschr. f. diatet. phys. ther., 1904, 7, 67. 
7. Bourne, G., and Smith, R. G., The value of intravenous and intraperitoneal administration of oxygen. Am. J. Physiol., 1927, 82, 328.

8. Singh, I., Intravenous injection of oxygen with the animal under ordinary and increased atmospheric pressure. J. Physiol, 1935, 84, 315.

9. Dick, M., Respiratory and circulatory responses to intravenous oxygen and their relation to anoxemia. Am. J. Physiol., 1939, 127, 228.

10. Grodins, F. S., Ivy, A. C., and Adler, H. F., Intravenous administration of oxygen. J. Lab. \& Clin. Med., 1943, 28, 1009.

11. Binger, C. A. L., Brow, G. R., and Branch, A., Experimental studies on rapid breathing. I. Tachypnea, independent of anoxemia, resulting from multiple emboli in the pulmonary arterioles and capillaries. J. Clin. Invest., 1924, 1, 127.

12. Behnke, A. R., Thomson, R. M., and Shaw, L. A., The rate of elimination of dissolved nitrogen in man in relation to the fat and water content of the body. Am. J. Physiol., 1935, 114, 137.

13. Behnke, A. R., Application of measurements of nitrogen elimination to the problem of decompressing divers. U. S. Nav. Med. Bull., 1937, 35, 219.

14. Behnke, A. R., The absorption and elimination of gases of the body in relation to its fat and water content. Medicine, 1945, 24, 359.

15. Whiteley, A. H., McElroy, W. D., Warren, G. H., and Harvey, E. N., Bubble formation in animals. V. Denitrogenation. J. Cell. and Comp. Physiol., 1944, 24, 257.

16. Whitaker, D. M., Blinks, L. R., Berg, W. R., Twitty, V. C., and Harris, M., Muscular activity and bubble formation in animals decompressed to simulated altitudes. J. Gen. Physiol., 1945, 28, 213.
17. Eggleton, P., Elsden, S. R., Fegler, J., and Hebb, C. E., A study of the effects of rapid decompression in certain animals. J. Physiol., 1945, 104, 129.

18. Whiteley, A. H., and McElroy, W. D., Denitrogenation of muscle and fat tissues of the anesthetized cat. Am. J. Physiol., 1946, 146, 229.

19. Karel, L., and Weston, R. E., The nitrogen content of femoral arterial and venous blood in anesthetized dogs during denitrogenation by continuous inhalation of 99.6 per cent oxygen-In press.

20. Edwards, G. A., Scholander, P. F., and Roughton, F. J. W., Micro gasometric estimation of the blood gases. III. Nitrogen. J. Biol. Chem., 1943, 148, 565.

21. Roughton, F. J. W., and Scholander, P. F., Micro gasometric estimation of the blood gases I. Oxygen. J. Biol. Chem., 1943, 148, 541.

22. Van Slyke, D. D., and Neill, J. M., The determination of gases in blood and other solutions by vacuum extraction and manometric measurement. J. Biol. Chem., 1924, 61, 523.

23. Horvath, S. M., and Roughton, F. J. W., Improvements in the gasometric estimation of carbon monoxide in blood. J. Biol. Chem., 1942, 144, 747.

24. Drinker, C. K., Pulmonary Edema and Inflammation. Harvard Univ. Press, Cambridge, 1945.

25. Goodwin, W. E., Harmel, M., and Lamont, A., Experiments with intravascular gases: oxygen and helium-to be published.

26. Adriani, J., The Chemistry of Anesthesia. Charles C. Thomas, Springfield, Ill., 1946.

27. Langmuir, I., Cold Spring Harbor Symp. Quant. Biol. 1938, 6, 136.

28. Marshall, E. K., Jr., and Rosenfeld, M., Depression of respiration by oxygen. J. Pharmacol. Exper. Therap., 1936, 57, 437. 